m (accessed 9 Aug 2010).

3. Carelli F. Family medicine crisis? Synapse Magazine $2009 ; 12$.

DOI: 10.3399/bjgp10X515485

\section{Loch Eport}

A few comments on Alec Logan's paragraph and photograph. ${ }^{1}$ His latitude and longitude, I'm sure, are immaculate and the exquisite pink flowers are Thrift or Sea Pink (Armeria maritima), that grow in great profusion on the Hebridean coasts in summer. The loch pictured however, is Lochmaddy, not Locheport and the hill is Eaval, not Heaval, that every BJGP reader must know is on the island of Barra! I agree with nomenclature, that almost every hill in the Outer Hebrides has the Norse suffix -val (fjall or Fell). I was born and lived there, until I left for the first time aged 15 to further my schooling. I appreciate his kind remarks about my native isle and wish him many happy returns.

\section{Alastair Morrison, Sidinish, Ferntower Road, Crieff, PH7 3DH. E-mail: gpmorrison@secaurazone.net}

\section{REFERENCE}

1. Logan A. Loch Eport. Br J Gen Pract 2010; 60(576): 547.

DOI: 10.3399/bjgp10X515502

\section{Smoking cessation}

I read with interest the leader by Patrick White. ${ }^{1}$ I share his enthusiasm for smoking cessation and pulmonary rehabilitation. I do not, however, share his enthusiasm for inhaler therapy beyond short-term betaagonists. The evidence for long-term reductions in exacerbations and admissions is there but it is hardly striking. I do not think that we should extrapolate reductions in mortality until that evidence is there. The fact that it is not already, suggests that any reductions, sadly, won't be too great.
My concerns are that, once labelled the path of prescribing moves almost automatically to short-acting betaagonists, long-acting beta-agonists, and inhaled steroids in all patients, even in those with mild disease and even in those with no objective or subjective hard evidence of improvement. How can we make treatment more objectively useful?

I do not want to be a therapeutic nihilist but equally this disease needs cost effective, evidence-based treatments that are re-assessed and stopped if they don't work. A huge sum is being spent promoting the benefits of multiple treatments, but rarely do these promotions emphasise, for instance, the increased pneumonias in people with chronic obstructive pulmonary disease who are being treated with inhaled steroids.

\section{John Sharvill,}

GP, Balmoral Surgery, Canada Road, Deal, Kent, CT14 7EQ.

E-mail: john.sharvill@nhs.net

\section{REFERENCE}

1. White P. COPD in primary care: a time of opportunity. Br J Gen Pract 2010; 60(576): 477-478.

DOI: 10.3399/bjgp10X515494

\section{MMR and egg allergy: to vaccinate or not to vaccinate?}

We do receive a number of referrals every year (10-15) from GPs for MMR to be administered in a hospital setting. The live measles and mumps vaccine is grown on cultured chick embryo fibroblasts and there is a concern that there could be some amount of egg protein in the vaccine. The controversy surrounding MMR and egg allergy has been long standing even though the hen's egg protein in the vaccine is highly processed and the concentrations are very low to trigger any allergic reaction. ${ }^{1}$ There has been a vast amount of evidence ${ }^{2,3}$ published already about the safety of MMR in children with egg allergy. In spite of various recommendations and guidelines, children are still being referred for MMR to be administered in a hospital setting.

The guidance in the UK surrounding MMR and egg allergy has changed over the years. The recommendations for MMR vaccine in egg allergic children were published in 2000. ${ }^{1}$ It stated that children with mild egg allergy can be safely vaccinated in primary care and recommended that children with previous significant allergic reactions should be vaccinated in hospital. Most of our practice is still based on these recommendations.

The latest British Society of Allergy and Clinical Immunology (BSACl) guidance recommends that all children with egg allergy should be immunised in primary care. 'Children who have had documented anaphylaxis to the vaccine itself should be assessed by an allergist'. ${ }^{4}$

Our approach has always been to write back to GPs or to speak to them directly about the safety of MMR in egg allergy. We, however, do not know if any of these children did ever go on to have the vaccine in primary care.

We agree with the recommendation by Ainsworth et a ${ }^{5}$ of attaching a copy of $\mathrm{BSACl}$ guidelines when we write back to our GPs. Although the guidelines have been published, there is still a possibility that many of our colleagues in primary care are not aware of them. We believe that inclusion of these recommendations in all the immunisation leaflets and related websites would lead to increased awareness and reduce the confusion surrounding this controversy. We hope that the green book would include the same advice in its next edition.

Srinivas Bandi, Consultant Paediatrician, University Hospital Coventry, Clifford Bridge Road, Coventry, CV2 2DX. E-mail: seenu_dr@hotmail.com

Colin MacDougall,

Consultant Paediatrician, University Hospital Coventry, Clifford Bridge Road, Coventry. 


\section{REFERENCES}

1. Khakoo GA, Lack G. Recommendations for using MMR vaccine in children allergic to eggs. BMJ 2000; 320(7239): 929-932.

2. James JM, Burks AW, Roberson PK, Sampson HA. Safe administration of the measles vaccine to children allergic to eggs. N Engl J Med 1995; 332(19): 1262-1266.

3. Aickin R, Hill D, Kemp A. Measles immunisation in children with allergy to egg. $B M J 1994 ; 309(6949)$ : 223-225.

4. Clark AT, Skypala I, Leech SC, et al. British Society for Allergy and Clinical Immunology guidelines for the management of egg allergy. Clin Exp Allergy 2010 40(8): 1116-1129.

5. Ainsworth E, Debenham P, Carrol ED, Riordan FA. Referrals for MMR immunisation in hospital. Arch Dis Child 2010; 95(8): 639-641.

DOI: 10.3399/bjgp10X515511

\section{Physical activity promotion}

Davies and Garbutt wrote an important and commendable editorial on exercise prescription; ${ }^{1}$ however, there are some fundamental issues raised requiring clarification and further consideration.

First, when measured objectively, a staggering $95 \%$ of the adult population (UK and US) do not meet the minimum recommended levels of physical activity to confer basic health benefits. ${ }^{2,3}$

Second, most chronic diseases reflect the pandemic syndrome of physical inactivity. This predisposes the inactive majority to osteoporosis, muscle atrophy, low back pain, coronary artery disease, peripheral artery disease, stroke, hypertension, type 2 diabetes, obesity, dyslipidemia, metabolic syndrome, some cancers (for example, breast cancer),
Alzheimer's disease, depression, pain, sleep problems, erectile dysfunction, death, and much more. ${ }^{4}$ Not only does physical activity prevent these unpleasant afflictions, but it should also be the very first treatment. ${ }^{5}$

Third, people seem to forget when reflecting on recommended guidelines for physical activity that they represent a minimum. Lets not forget there is a dose response to the level, duration, and intensity of physical activity (that is, the more you do and more vigorous, the greater the health benefits) and that something is better than nothing. Most guidelines state that about 30 minutes' moderate to vigorous physical activity on at least 5 days a week or equivalent is the recommended minimum, including the recent BASES guidelines, which update and address some of this apparent confusion. ${ }^{6}$

Fourth, practitioner learning needs extend far beyond lacking basic knowledge about physical activity/inactivity. We are also not trained in lifestyle behaviour change techniques, that poses a significant barrier to exercise promotion success. ${ }^{7}$

A recent survey confirms that the current optional 'Lets Get Moving' physical activity care pathway is not being used. Only $660(0.007 \%)$ of 9.5 million patients were found to have ever been coded for any of the GP Physical Activity Questionnaire read codes (March 2010

General Practice Research Gold Database). ${ }^{7}$

How sad if GPs will only wait until physical activity promotion is included in Quality and Outcomes Framework before implementing good medical practice and promoting physical activity to their patients at every appropriate opportunity.

Physical activity is a natural pill and both a cure and prevention for many ills. Given the way that modern medicine is practised and influenced, perhaps if we thought of physical inactivity as a disease in its own right and physical activity as a medication in the same way as prescribed drugs we may begin to make some progress to the benefit of nearly all our patients, the finances of the NHS, and society.

\section{Richard Weiler,}

Specialist Registrar in Sport \& Exercise Medicine, Imperial College Healthcare NHS Trust and Locum GP, Hertfordshire. E-mail: rweiler@doctors.org.uk

\section{REFERENCES}

1. Davies P, Garbutt G. The exercise prescription. $\mathrm{Br}$ Gen Pract 2010; 60(577): 555-556.

2. NHS Information Centre. Health survey for England 2008: physical activity and fitness. 2009. www.ic.nhs.uk/statistics-and-data-collections/healthand-lifestyles-related-surveys/health-survey-forengland/health-survey-for-england--2008-physicalactivity-and-fitness (accessed 9 Aug 2010).

3. Troiano RP, Berrigan D, Dodd KW, et al. Physical activity in the United States measured by accelerometer. Med Sci Sports Exerc 2008; 40(1): 181-188.

4. Weiler R, Stamatakis E, Blair S. Should health polic focus on physical activity rather than obesity? Yes. BMJ 2010; 340: c2603.

5. Stamatakis E, Weiler R. Prevention of cardiovascular disease: why do we neglect the most potent intervention? Heart 2010; 96(4): 261-262.

6. O'Donovan G, Biddle S, Blazevich A, et al. The ABC of Physical Activity for Health: a consensus statement from the British Association of Sport and Exercise Sciences. J Sports Sci 2010; 28(6): 573-591.

7. Weiler R, Stamatakis E. Physical activity in the UK: a unique crossroad? Br J Sports Med 2010. [Epub ahead of print]

DOI: 10.3399/bjgp10X515520 